\title{
Mechanisms of Low-temperature Tolerance in Cucumber Leaves of Various Ages
}

\author{
Yong In Kuk ${ }^{\mathbf{1}}$ and Ji San Shin \\ Faculty of Applied Plant Science, Chonnam National University, Gwangju 500-757, South Korea
}

\begin{abstract}
AdDitional INDEX words. antioxidative enzyme, chlorophyll a fluorescence, Cucumis sativus, isozyme profile, lipid peroxidation

Abstract. To determine whether differential tolerance to paraquat among cucumber (Cucumis sativus $\mathrm{L}$.) leaves of various ages correlates with low-temperature tolerance, leaves of three cultivars at the four-leaf stage were exposed to $5^{\circ} \mathrm{C}$. Leaves tolerant to paraquat were also tolerant to low temperature as indicated by electrolyte leakage changes in leaf tissue, lipid peroxidation, and photosynthesis measurements. The youngest leaf (leaves were numbered 1 to 4 with the youngest leaf given 4) on the same plant was more tolerant than older leaves to low temperature. During chilling, lipid peroxidation and $\mathrm{H}_{2} \mathrm{O}_{2}$ content increased in the oldest leaf when compared with the three younger leaves. Photosynthetic activity and chlorophyll a fluorescence $\left(F_{v} / F_{m}\right)$ were significantly lower in leaf 1 than in leaf 4 . There was no difference in superoxide dismutase, catalase, ascorbate peroxidase (APX), and glutathione reductase activities among various leaf ages in untreated plants. Induction of antioxidant activity in response to low temperature was higher in the youngest leaf than in the oldest leaf. Expression of APX isozymes increased in response to low temperature, and their expression was the highest in the youngest leaf. Current results support earlier findings that antioxidant protection also was a mechanism for paraquat tolerance.
\end{abstract}

Low temperature is detrimental to plant growth and development and thus affects the productivity of important warmseason food crops worldwide. Cucumber, for example, is susceptible to low temperatures throughout its growth cycle (Jackman et al., 1988; Wang, 1990). Various mechanisms have been suggested to account for chilling (CI) or tolerance in plants. Some of the changes related to low-temperature stress include alterations in gene expression, proteins, lipids, carbohydrate composition, membrane properties, solute leakage, mitochondrial respiration, and photosynthesis (Basra, 2001; Guy, 1990; Prasad, 1996; Wise and Naylor, 1987).

Another mechanism involves a biochemical defense against membrane lipid peroxidation incited by increased generation of active oxygen species (AOS) such as superoxide $\left(\mathrm{O}_{2} \cdot\right)$, hydrogen peroxide $\left(\mathrm{H}_{2} \mathrm{O}_{2}\right)$, hydroxyl radical $(\cdot \mathrm{OH})$, and singlet oxygen $\left({ }^{1} \mathrm{O}_{2}\right)$ in response to chilling (Havaux and Davaud, 1994; Terashima et al., 1994). Active oxygen species may cause a cascade of oxidative reactions of cellular components, and they have been implicated in photoinhibition and cellular damage in chilling-susceptible plants exposed to low temperatures (Hetherington et al., 1989; Wise and Naylor, 1987). Plants have evolved mechanisms to protect cellular membranes and organelles from the damaging effects of AOS by increasing the activity of antioxidative enzymes to neutralize AOS (Oidaira et al., 2000; Wise and Naylor, 1987).

Both enzymatic and nonenzymatic systems protect tissue from AOS, which are generated as a result of environmental stresses such as drought and low temperature. Members of the enzymatic antioxidant defense system include superoxide dismutase (SOD; EC 1.15.1.1), ascorbate peroxidase (APX;

Received for publication 18 Sept. 2006. Accepted for publication 26 Jan. 2007. This work was supported by the Korea Research Foundation (KRF-2003-005C00026).

${ }^{1}$ Corresponding author. E-mail: yikuk@chonnam.ac.kr.
EC 1.11.1.11), catalase (CAT; EC 1.11.1.6), and an ascorbateglutathione cycle that includes glutathione reductase (GR; EC 1.6.4.2). Several small antioxidant molecules, such as ascorbic acid, glutathione, $\alpha$-tocopherol, carotenoids, and flavonoids, can quench many kinds of AOS (Halliwell and Gutteridge, 1989).

There appears to be a relationship between antioxidant enzyme activity and chilling tolerance. In chilling-tolerant cucumber cultivars, SOD and APX activity levels were higher than that of the chilling-susceptible cultivars (Shen et al., 1999). In rice (Oryza sativa L.) plants, SOD activities were induced when the rice plants were transferred from 25 to $5{ }^{\circ} \mathrm{C}$, but CAT activity decreased in both sensitive and resistant rice cultivars at $5{ }^{\circ} \mathrm{C}$ (Saruyama and Tanida, 1995). Similar results were reported for pea (Pisum sativum L.), cucumber, maize (Zea mays L.), rye (Secale cereale M. Bieb.), and wheat (Triticum aestivum L.) (Feierabend et al., 1992; Mishra et al., 1993; Omran, 1980). The activities of CAT, APX, and monodehydroascorbate reductase were suspected of contributing to chilling tolerance in the early stages of development in maize (Hodges et al., 1997). Furthermore, acclimationinduced tolerance has been reported to be developmentally regulated in maize seedlings. This developmentally regulated tolerance was correlated with induced CAT activities in which younger seedlings were shown to have higher CAT activity than older ones. Differences in CAT levels were correlated with a higher percentage of the younger seedlings surviving chilling stress.

Paraquat is a quick-acting contact herbicide that immediately kills cells/tissues that get in contact with the herbicide. In a young leaf, however, damaged cells can be replaced quickly by the differentiating cells of the rapidly expanding leaf. Also, high levels of antioxidant activity in young cucumber leaves reduce paraquat damage (Kuk et al., 2006). A similar scenario of developmental regulation exists in pea leaves, for which resistance to paraquat was correlated with leaf age, GR, and 
$\mathrm{Cu} / \mathrm{Zn}$ SOD transcript levels (Donahue et al., 1997). Consequently, it was hypothesized that there could also be differential tolerance to chilling stress between cucumber leaves. Although the mechanisms of CI and tolerance have been studied in cucumber plants (Kuk et al., 2003b; Reyes and Jennings, 1994; Terashima et al., 1994), there is little research regarding the effect of leaf age on tolerance to low temperatures, and it is not known whether tolerance to paraquat correlates with tolerance to chilling stress in cucumber leaves.

The objectives of this research were to determine whether differential tolerance among cucumber leaves of various ages to paraquat stress also correlates with low-temperature tolerance, and to examine whether changes in antioxidant levels were related to variability in low-temperature tolerance.

\section{Materials and Methods}

Plant growth and treatment conditions. Among 11 cultivars, three cultivars of cucumber (Kyeoulsalicheongjang, Baekbongdadagi, and Jangbaekdadagi) were selected based on evidence of differential paraquat tolerance at different leaf ages in previous research (Kuk et al., 2006). Leaf injury for these three cultivars was less than that of eight other cultivars tested, averaged over leaf age and herbicide rate. The level of foliar injury incited by paraquat was leaf $1>2>3>4$ in 7 of 11 cultivars used, where leaf 4 was the youngest leaf. These three cultivars showed clear difference between leaf age classes in response to paraquat and were, therefore, selected for further study. Seeds were obtained from Seminis Korea Co. (Seoul, Korea). Seeds were sown in plug trays $(50 \times 30 \times 7 \mathrm{~cm})$. The trays contained commercial growing substrate [peatmoss, vermiculite, and zeolite (Boo-Nong Soil, Seoul, Korea)], and the plants were allowed to germinate in the greenhouse at $30 \pm 3 / 20 \pm 3{ }^{\circ} \mathrm{C}$ day/night temperatures. The germinated seedlings were transplanted into $500-\mathrm{mL}$ pots (one plant per pot) containing commercial growing substrate and placed in the growth chamber (VS-91G09-H-1300; Vision Scientific Co., Buchon-si, Korea) until the plants reached the four-leaf stage. The growth chamber was maintained at $30 / 25{ }^{\circ} \mathrm{C}$ day/night temperatures with a 14 -h photoperiod and $70 \%$ relative humidity. The photosynthetic photon flux $(P P F)$ on the plant canopy was $250 \mu \mathrm{mol} \cdot \mathrm{m}^{-2} \cdot \mathrm{s}^{-1}$. The seedlings were watered daily and were given half-strength Hoagland's nutrient solution every $7 \mathrm{~d}$ until treatments were imposed.

At the four-leaf stage, the plants were exposed to the growth chamber (SW-130C; Sangwoo Technical, Gyunggi, Korea) at $5{ }^{\circ} \mathrm{C}$, for $6,12,24,48$, and $72 \mathrm{~h}$. During the low-temperature treatment, the $P P F$ on the plant canopy was $250 \mu \mathrm{mol} \cdot \mathrm{m}^{-2} \cdot \mathrm{s}^{-1}$. Other conditions were the same as those described in the previous growth chamber. When the treatment was initiated, leaf 4 was partially expanded on $50 \%$ of the plants. Leaves 1 , 2 , and 3 were fully open with an average leaf width of about $12 \mathrm{~cm}$. Leaf 1 is the oldest. The experiments were conducted three times with six plants in each experiment, and used one set of controls ( $0 \mathrm{~h}$ after treatment). For the evaluation of various parameters, plants were harvested at $6,12,24,48$, and $72 \mathrm{~h}$ after treatment. Harvesting was done at the same time (1800 HR) for each treatment, except the 6-h harvest, to avoid complications from diurnal fluctuations in biochemical processes.

Evaluation of CI. Chilling was evaluated by measuring the amount of cellular leakage. This was accomplished by cutting out 4-mm-diameter leaf disks ( $0.2 \mathrm{~g}$ fresh weight) with a cork borer and placing the disks in a $6-\mathrm{cm}$-diameter polystyrene Petri dish containing $5 \mathrm{~mL} 1 \%$ sucrose and $1 \mathrm{~mm} 2-(N-$ morpholino)ethanesulfonic acid $(\mathrm{Ph}, 6.5)$. The leaf disks were incubated in the growth chamber (VS-91G09-H-1300; Vision Scientific Co.) at $25^{\circ} \mathrm{C}$ for $2 \mathrm{~h}$. Every $30 \mathrm{~min}$, the trays containing the disks were gently shaken by hand for $\approx 1 \mathrm{~min}$ (Reyes and Jennings, 1994). Electrolyte leakage from the leaf disks into the bathing medium was subsequently measured using a conductivity meter (EW-01481-61; Cole-Parmer Instrument Co., Vernon Hills, Ill.). Because of the difference in background conductivity between treatments, data were expressed as changes in conductivity relative to an initial measurement. The electrolyte leakage levels recorded just before chilling were used as initial measurements. All treatments were replicated three times, and conductivity values were expressed on a gram per fresh weight basis.

All three cultivars used in this study showed a distinct difference between leaf ages in response to low temperature. However, 'Baekbongdadagi' showed more tolerance than the other two cultivars to low temperature, so this cultivar was used for further study.

LIPID PEROXIDATION. Lipid peroxidation was estimated by quantifying the amount of malondialdehyde (MDA) production using a slight modification of the thiobarbituric acid (TBA) method as previously described by Buege and Aust (1978). Each leaf $(0.5 \mathrm{~g})$ was harvested at $0,6,12,24,48$, and $72 \mathrm{~h}$ after treatment. The leaf was homogenized using a mortar and pestle in $5 \mathrm{~mL} 0.5 \%$ TBA in $20 \%$ trichloroacetic acid. The homogenate was then centrifuged at $20,000 \mathrm{~g}_{\mathrm{n}}$ for $15 \mathrm{~min}$, and the supernatant was collected. The supernatant was heated in a boiling water bath for $25 \mathrm{~min}$ and was allowed to cool in an ice bath. After additional centrifugation at $20,000 \mathrm{~g}_{\mathrm{n}}$ for $15 \mathrm{~min}$, the resulting supernatant was used for the spectrophotometric determination of MDA. Absorbance at $532 \mathrm{~nm}$ for each sample was recorded and subtracted for nonspecific turbidity at $600 \mathrm{~nm}$. Malondialdehyde concentrations were calculated using a molar extinction coefficient of $156 \mathrm{~mm} \mathrm{~mm}^{-1} \cdot \mathrm{cm}^{-1}$ and the following formula: MDA (micromoles per gram dry weight $)=\left[\left(\mathrm{A}_{532}-\mathrm{A}_{600}\right) / 156\right] \times 10^{3} \times$ dilution factor $(\mathrm{Du}$ and Bramlage, 1992).

Chlorophyll a Fluorescence. Chlorophyll a fluorescence was measured in vivo at room temperature after the chilling treatment on each day using a pulse amplitude modulation fluorometer (PAM-2000; Walz, Effeltrich, Germany). Before measuring fluorescence, leaf clips were attached to selected leaflets, and the leaves were adapted to darkness for $10 \mathrm{~min}$ to fully open all photosystem (PS) II reaction centers (oxidize Qa), and also to dissipate the transthylakoid $\mathrm{pH}$ gradient to eliminate nonphotochemical quenching (Krause et al., 1983). A minimal fluorescence yield, $\mathrm{F}_{0}$, was obtained upon excitation of the leaves with a weak measuring beam of $0.12 \mu \mathrm{mol} \cdot \mathrm{m}^{-2} \cdot \mathrm{s}^{-1}$ from a pulse light-emitting diode. A maximum fluorescence yield, $\mathrm{F}_{\mathrm{m}}$, was determined after exposure to a saturating pulse of white light $\left(1 \mathrm{~s}, 4500 \mu \mathrm{mol} \cdot \mathrm{m}^{-2} \cdot \mathrm{s}^{-1}\right)$ to reduce all reaction centers. The ratio of variable to maximum fluorescence $\left(\mathrm{F}_{\mathrm{v}} / \mathrm{F}_{\mathrm{m}}\right)$ derived from the measurement was used as an estimate of the maximum photochemical efficiency of PS II (Butler, 1978).

Net Photosynthesis. Net photosynthesis, measured as $\mathrm{CO}_{2}$ uptake, was determined using an open gas analysis system (LI-6400; LI-COR, Lincoln, Nebr.) on four expanded leaves, from each leaf age class, $48 \mathrm{~h}$ after treatment under the 
following conditions. The light intensity was $2000 \mu \mathrm{mol} \cdot \mathrm{m}^{-2} \cdot \mathrm{s}^{-1}$ $P P F, \mathrm{CO}_{2}$ for the sample chamber was $400 \mu \mathrm{L} \cdot \mathrm{L}^{-1}$, relative humidity was $40 \pm 3 \%$, and the leaf temperature for the chamber air was $25 \pm 0.5^{\circ} \mathrm{C}$. A completely randomized design was used in this study. Data were analyzed by analysis of variance, and means were compared using Duncan's multiple range test in SAS (version 7; SAS Institute Inc., Cary, N.C.).

Hydrogen peroxide content. The $\mathrm{H}_{2} \mathrm{O}_{2}$ level was measured colorimetrically as described by Jana and Choudhuri (1982). Hydrogen peroxide was extracted by homogenizing $0.2 \mathrm{~g}$ of leaves with $3 \mathrm{~mL}$ phosphate buffer $(50 \mathrm{~mm} ; \mathrm{pH}, 6.8)$. The homogenate was centrifuged at $6000 \mathrm{~g}_{\mathrm{n}}$, for $25 \mathrm{~min}$. To determine $\mathrm{H}_{2} \mathrm{O}_{2}$ levels, $3 \mathrm{~mL}$ extracted solution was mixed with $1 \mathrm{~mL} 0.1 \%$ titanium chloride (Aldrich, St. Louis) in $20 \%(\mathrm{v} / \mathrm{v}) \mathrm{H}_{2} \mathrm{SO}_{4}$, and the mixture was centrifuged, at $6000 \mathrm{~g}_{\mathrm{n}}$, for $15 \mathrm{~min}$. The intensity of the yellow supernatant was measured at $410 \mathrm{~nm}$. The $\mathrm{H}_{2} \mathrm{O}_{2}$ level was calculated using the extinction coefficient $0.28 \mu \mathrm{m}^{-1} \cdot \mathrm{cm}^{-1}$. Photoperiod and light exposure period were the same as those described in the previous experiment on plant growth and treatment conditions.

Protein extraction. Frozen leaves $(0.5 \mathrm{~g})$ were pulverized in liquid $\mathrm{N}_{2}$ using a mortar and pestle, and then resuspended in $3 \mathrm{~mL} 100 \mathrm{~mm}$ potassium phosphate buffer $(\mathrm{pH}, 7.5)$ containing 2 mM ethylenediaminetetraacetic acid, 1\% polyvinylpyrrolidone40, and $1 \mathrm{~mm}$ phenylmethylsulfonyl fluoride. For the APX assay, the extraction buffer also contained $5 \mathrm{~mm}$ ascorbate. The suspension was centrifuged at $15,000 \mathrm{~g}_{\mathrm{n}}$ for $20 \mathrm{~min}$ at $4{ }^{\circ} \mathrm{C}$, and the resulting supernatant was used directly as an enzyme source. For the SOD assays, however, the supernatant was eluted through a Sephadex G-25 M minicolumn (PD-10; Pharmacia, Uppsala, Sweden) at $4{ }^{\circ} \mathrm{C}$ using $100 \mathrm{~mm}$ potassium phosphate buffer $(\mathrm{pH}, 7.5)$ to remove any low-molecular weight inhibitors (Anderson et al., 1995). The protein concentration was determined according to the method of Bradford (1976) using bovine serum albumin as a standard. Photoperiod and light exposure period were the same as those described in the previous experiment on plant growth and treatment conditions.

ENZYME ASSAYS. All the enzymes were assayed in a $1-\mathrm{mL}$ cuvette at 24 to $26{ }^{\circ} \mathrm{C}$. The activity was linear with respect to time and the enzyme concentrations. Absorbance of samples was determined using an ultraviolet/visual wavelength spectrophotometer (Ultrospec 4000; Pharmacia Biotech, Cambridge, UK) operated in the split-beam mode. The SOD activity was assayed by the extent of inhibition of cytochrome $\mathrm{c}$ reduction by measuring the superoxide generated in a xanthine-xanthine oxidase system (Spychalla and Desborough, 1990). One unit of SOD was defined as the amount of enzyme that inhibited the rate of cytochrome c reduction by $50 \%$. Catalase activity was assayed according to the method of Mishra et al. (1993) by monitoring the decline in absorbance at $240 \mathrm{~nm}(\varepsilon=36$ $\mathrm{m}^{-1} \cdot \mathrm{cm}^{-1}$ ) as a result of $\mathrm{H}_{2} \mathrm{O}_{2}$ degradation. The APX activity was estimated with the method of Chen and Asada (1989) by monitoring the decline in absorbance at $290 \mathrm{~nm}$ as ascorbate $\left(\varepsilon=2.8 \mathrm{~mm}^{-1} \cdot \mathrm{cm}^{-1}\right)$ was oxidized. Glutathione reductase was measured with the method of Rao et al. (1996) by monitoring the decline in absorbance at $340 \mathrm{~nm}$ as nicotinamide adenine dinucleotide phosphate (NADPH) $\left(\varepsilon=6.2 \mathrm{~mm}^{-1} \cdot \mathrm{cm}^{-1}\right)$ was oxidized. Data were expressed as percentages (based on total soluble protein) of the control values at each leaf age.

Native POLYACRYlamide Gel Electrophoresis AND ACTIVITY STAINING. The isozymes of APX were separated on nondenaturating polyacrylamide gels, according to methods described by Laemmli (1970), with only slight modifications. Equal amounts of protein extracts were mixed with bromophenol blue and glycerol to a final reaction concentration of $12.5 \%$ $(\mathrm{v} / \mathrm{v})$ and loaded on $10 \%$ polyacrylamide gels. The proteins were separated by electrophoresis at $4{ }^{\circ} \mathrm{C}$ for $3 \mathrm{~h}$ with a constant current of $30 \mathrm{~mA}$. However, $2 \mathrm{~mm}$ ascorbate was added to the electrode buffer $(\mathrm{pH}, 8.3)$, and the gel was prerun for $30 \mathrm{~min}$ before the sample was loaded (Mittler and Zilinskas, 1993). The APX isozymes were visualized using the methods described by Rao et al. (1996). Staining reaction was stopped with $7.5 \%$ glacial acetic acid. The gels were then stored at $4{ }^{\circ} \mathrm{C}$ in plastic boxes containing $7.5 \%$ acetic acid solution until photographic recording.

\section{Results}

Physiological responses to low temperature. There was no difference in cellular leakage between leaves 3 and 4 during the chilling period among cultivars except for 'Kyoulsalicheongjang' at $72 \mathrm{~h}$ (Fig. 1). However, cellular leakage was consistently higher in leaf 1 (oldest leaf) than in younger leaves. In general, the level of cellular leakage incited by low temperature on each leaf was on the order of leaf $1>2>3=$ 4 in all cultivars used.

LIPID PEROXIDATION. Except for leaf 4, the levels of MDA indicated that lipid peroxidation increased generally with chilling periods. However, in leaves 1, 2, and 3, the increase was minimal at certain chilling periods (Fig. 2A). Generally, the level of lipid peroxidation resulting from low temperature was on the order of leaf $1=2>3>4$.

Chlorophyll a Fluorescence. Chlorophyll a fluorescence $\left(\mathrm{F}_{\mathrm{v}} / \mathrm{F}_{\mathrm{m}}\right)$ was the same in all leaves of untreated plants at the onset of the experiment (Fig. 2B). Low temperature rapidly reduced chlorophyll a fluorescence in all leaves regardless of age, but the decline in chlorophyll a fluorescence was least in the youngest leaf up to $48 \mathrm{~h}$ after treatment. Continued exposure to chilling temperature beyond this time had a detrimental effect even on the youngest leaf. The level of chlorophyll a fluorescence in all leaf ages during the first $48 \mathrm{~h}$ of low temperature was generally on the order of leaf $4>3=2>1$. Based on the lipid peroxidation and chlorophyll a fluorescence studies, the youngest leaf was more tolerant to chilling than the older leaves.

Рнотоsynthetic activity. The apparent level of photosynthesis in untreated leaves 1, 2, 3, and 4 was similar (Fig. 3). However, the photosynthetic activity of the youngest leaf was higher than that of the older leaves $48 \mathrm{~h}$ after chilling treatment.

Hydrogen peroxide content. The levels of $\mathrm{H}_{2} \mathrm{O}_{2}$ were similar in all four leaf ages, up to $24 \mathrm{~h}$, after chilling treatment. However, the levels of $\mathrm{H}_{2} \mathrm{O}_{2}$ were on the order of leaf $1=2>$ $3>4,48 \mathrm{~h}$ after treatment, and leaf $1>2>3>4,72 \mathrm{~h}$ after treatment (Fig. 4).

ANTIOXIDANT ENZYMe ACTIVITIES IN RESPONSES TO LOW TEMPERATURE. Upon exposure to low temperature, the SOD activity in leaf 4 was induced relative to that of the untreated plant. The SOD activity in leaf 4 was higher than those of leaves 1, 2, and 3 over a 72-h period (Fig. 5A). Superoxide dismutase activities in leaves 1, 2, and 3 were only slightly induced or were unaffected by low-temperature treatment. Catalase activity was similar in all four leaf ages, up to $24 \mathrm{~h}$, after chilling treatment (Fig. 5B). However, the CAT activities in leaves 2, 3, 


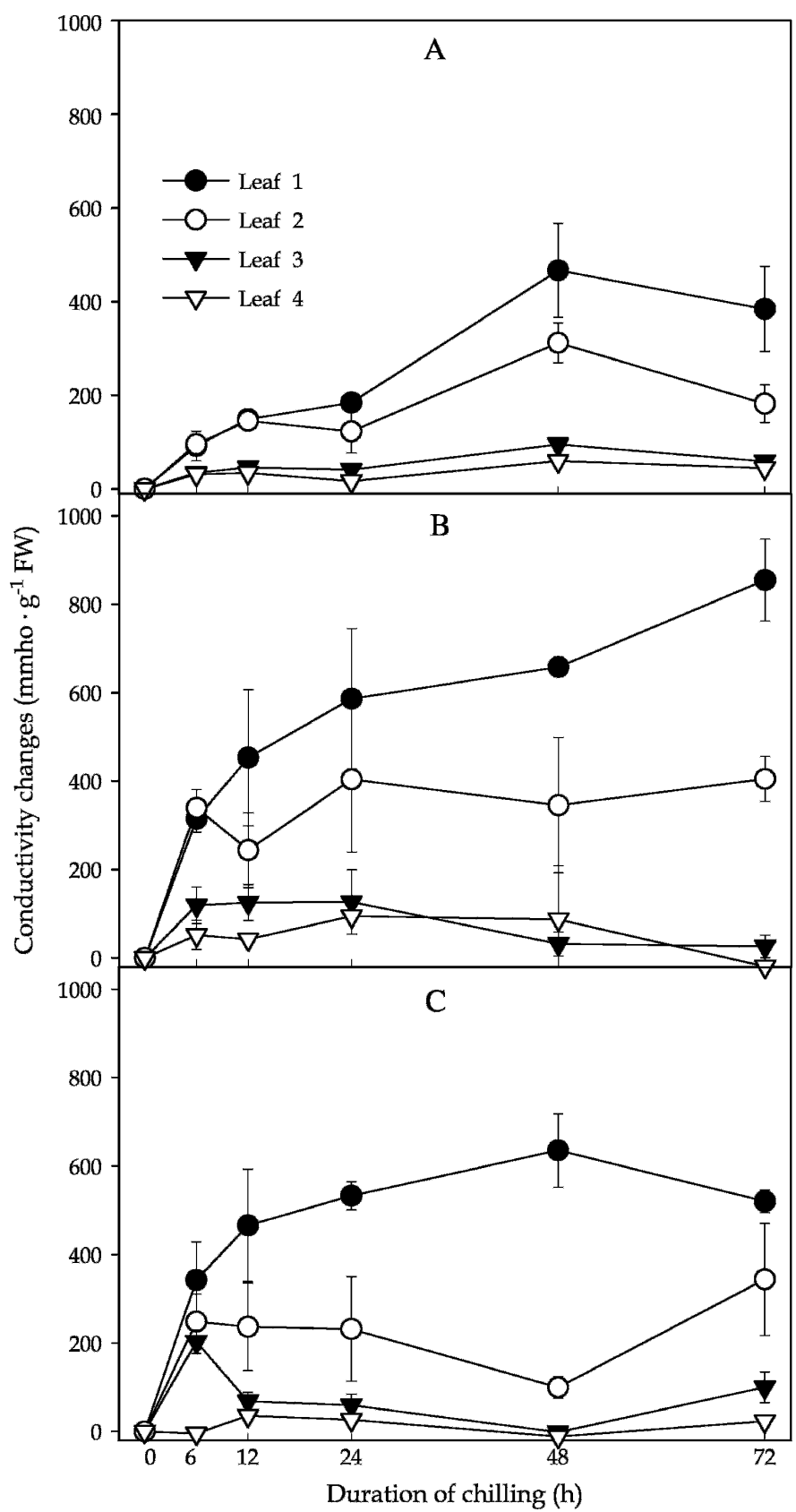

Fig. 1. Effect of low temperature on conductivity change, indicative of cell membrane damage, in cucumber leaves of various ages. (A) 'Baekbongdadagi'. (B) 'Jangbaekdadagi'. (C) 'Kyoulsalicheongjang'. Leaf 1 is the oldest. Values are the mean \pm SE of three replicates. In some cases, the error bar is obscured by the symbol. FW, fresh weight.

and 4 were higher than that of leaf 1 at $48 \mathrm{~h}$ and $72 \mathrm{~h}$ after exposure to low temperature. In contrast to SOD activity, CAT activities in all leaf ages decreased as a result of chilling stress. Ascorbate peroxidase activity in leaf 4 was generally higher than that of older leaves up to $72 \mathrm{~h}$ after chilling treatment (Fig. 5C). Similar to SOD, APX activity in all leaf ages was generally induced as a result of chilling stress, but induction of APX activity was higher in leaf 4 than in older leaves. Leaf age did not have a consistent impact on the effect of chilling stress on GR activity (Fig. 5D). Differences did exist between leaf ages at 6 and $72 \mathrm{~h}$ after exposure to chilling temperature; GR

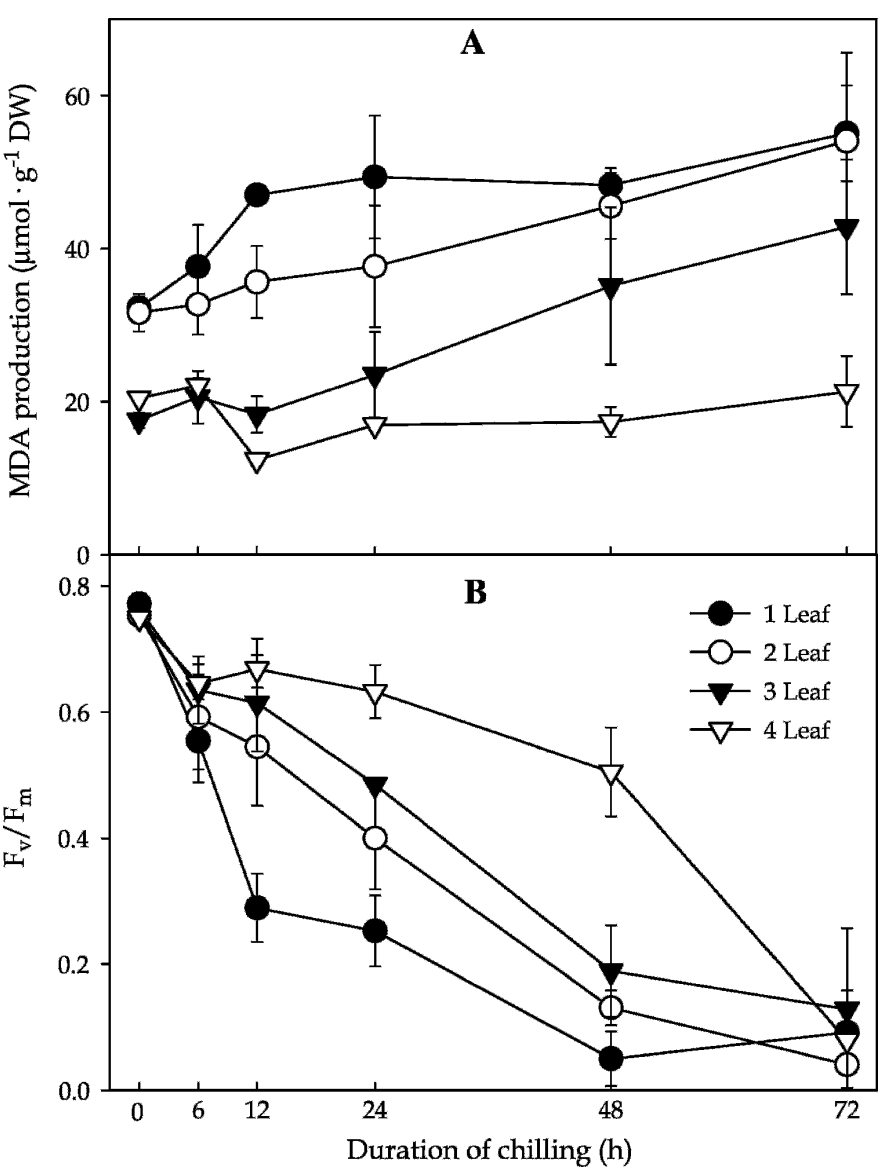

Fig. 2. (A, B) Effect of low temperature on malondialdehyde production $(\mathbf{A})$ and chlorophyll a fluorescence (B) of 'Baekbongdadagi' cucumber leaves. Leaf 1 is the oldest. Values are the mean \pm SE of three replicates. In some cases, the error bar is obscured by the symbol. DW, dry weight. $\mathrm{F}_{\mathrm{v}} / \mathrm{F}_{\mathrm{m}}$, chlorophyll a fluorescence; MDA, malondialdehyde.

activity was on the order of leaf $1<2=3<4$. The differential tolerance to chilling stress between cucumber leaves of various ages was obvious in SOD and APX activities, and, to some extent, induction of GR activities after chilling treatment.

AsCorbate PEROXIDASE ISOZYME PROFILE. We only analyzed APX isozymes because APX activity showed a better relationship between chilling tolerance and enzyme activities than other enzymes, SOD, CAT, and GR. There were four major forms of APX observed on the activity gels (Fig. 6). The band intensity of APX isozymes was higher in the treated leaves than in the control leaves. This indicates that chilling induced APX enzyme activity. Furthermore, the band intensity of APX isozymes in the youngest leaf (leaf 4) was higher than that of the older leaves of the control or treated plants 24 and $48 \mathrm{~h}$ after treatment.

\section{Discussion}

Numerous mechanisms responsive to chilling stress, such as lipid peroxidation, photosynthesis, and antioxidant gene expression, have been proposed to explain CI or chilling tolerance in plants (Basra, 2001; Wise and Naylor, 1987). Various experiments in this area have been conducted on cucumber (Kuk et al., 2003b; Reyes and Jennings, 1994; Terashima et al., 1994), among others. Data reported here 


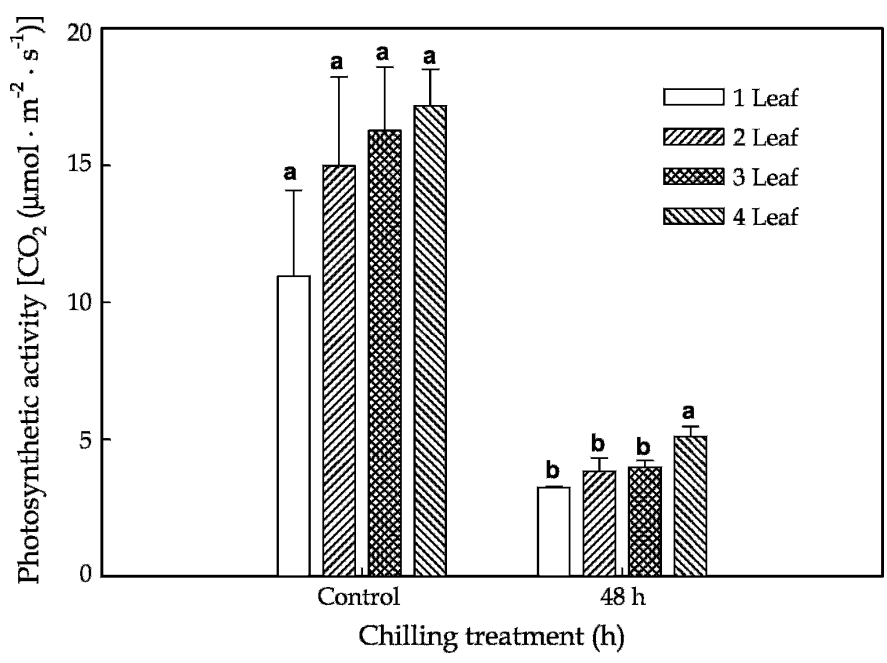

Fig. 3. Effect of low temperature on photosynthetic activity of 'Baekbongdadagi' cucumber leaves. Leaf 1 is the oldest. Values are the mean \pm sE of three replicates. In some cases, the error bar is obscured by the symbol. Means within bars followed by a different letter are significant by Duncan's multiple range test $(P=0.05)$.

stemmed from the finding that there is differential tolerance to chilling stress between cucumber cultivars. The different tolerance levels are the result of changes in the characteristics of the leaf surface structure, different absorption levels, and rapid metabolism of toxic compounds (Kuk et al., 2003a; Sherman et al., 1991). Older leaves have thicker cuticles and, therefore, tend to absorb less of the applied pesticide than younger leaves (Kuk et al., 2003a). The thicker leaf cuticle also serves as a better protection against injury from other external stress factors.

However, physiological and biochemical responses indicate less damage in the youngest leaf than older leaves when exposed to low temperature. There was less lipid peroxidation, less cellular leakage, less $\mathrm{H}_{2} \mathrm{O}_{2}$, and higher photosynthetic activity in younger leaves than in older leaves when exposed to

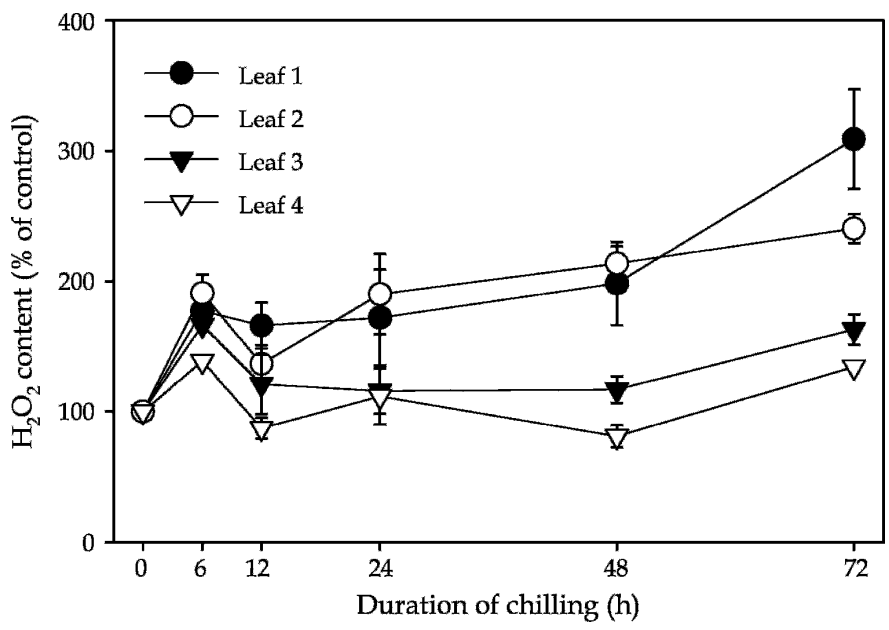

Fig. 4. Effect of low temperature on $\mathrm{H}_{2} \mathrm{O}_{2}$ content of 'Baekbongdadagi' cucumber leaves. Leaf 1 is the oldest. $\mathrm{H}_{2} \mathrm{O}_{2}$ content [measured in micromoles per gram fresh weight $(\mathrm{FW})]$ in control leaves was leaf $1,2.07 \mu \mathrm{mol} \cdot \mathrm{g} \mathrm{FW}$; leaf 2, $2.48 \mu \mathrm{mol} \cdot \mathrm{g} \mathrm{FW}$; leaf 3, 4.15 $\mu \mathrm{mol} \cdot \mathrm{g} \mathrm{FW}$; and leaf 4, $4.24 \mu \mathrm{mol} \cdot \mathrm{g} \mathrm{FW}$. Values are the mean $\pm \mathrm{SE}$ of three replicates. In some cases, the error bar is obscured by the symbol.

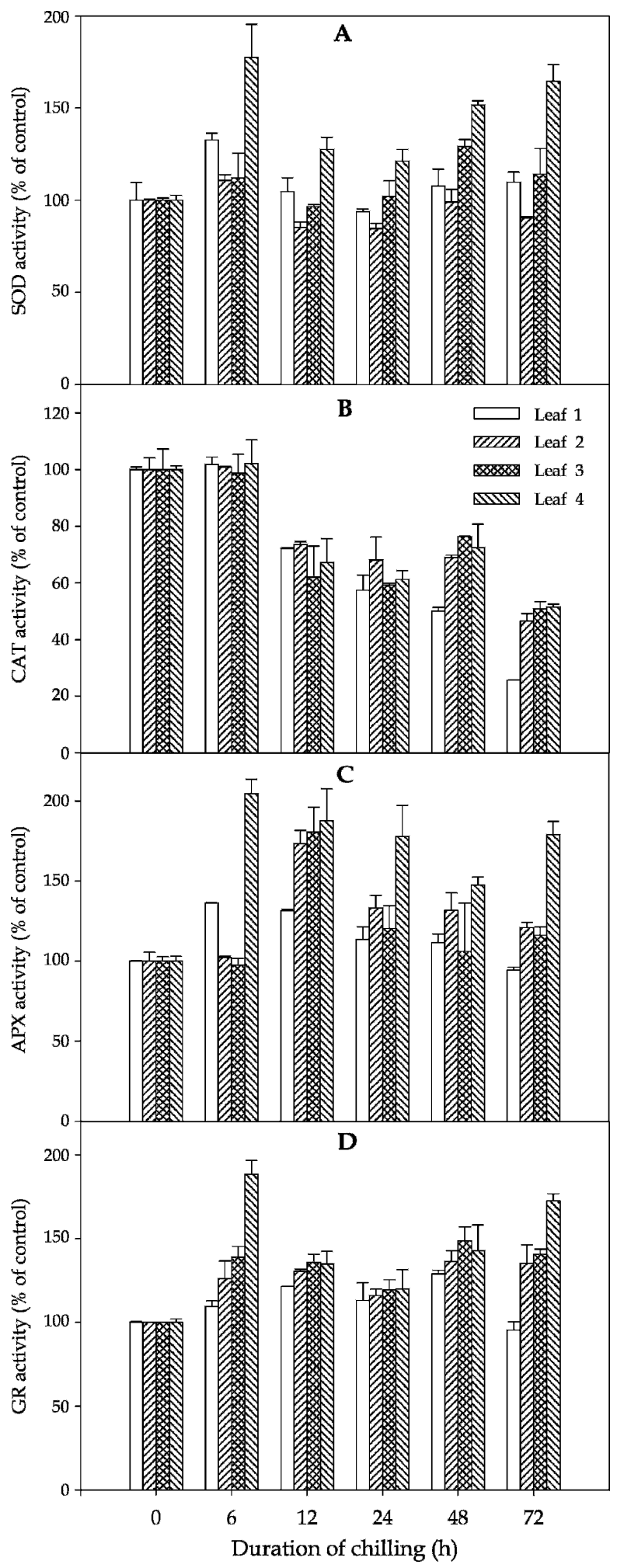

Fig. 5. (A-D) Effect of low temperature on superoxide dismutase (A), catalase (B), ascorbate peroxidase $(\mathbf{C})$, and glutathione reductase (D) activities of 'Baekbongdadagi' cucumber leaves expressed on a milligram protein basis. Leaf 1 is the oldest. Enzyme activities are expressed as percentages of the control values (enzyme units, milligrams of protein per hour). APX, ascorbate peroxidase; CAT, catalase; GR, glutathione reductase; SOD, superoxide dismutase. 
low temperature. Under optimal environmental conditions, light reaction and electron transport in photosynthesis lead to a minimal production of AOS. Consequently, some photooxidative damage occurs to chloroplasts, carotenoids, and proteins (Hetherington et al., 1989). At chilling temperatures, photoinhibition can occur at the light intensities below that of full sunlight. The extent of photoinhibition in leaves of chilling-resistant species such as pea and wheat was about half that measured in chilling-susceptible plants such as cucumber and maize. Photoinhibition was dependent both on temperature and light, increasing nonlinearly with decreasing temperature and linearly with increasing light intensity (Hetherington et al., 1989). Production of AOS triggers a series of deleterious processes, such as lipid peroxidation, degradation of proteins, and DNA damage in the cell (Halliwell and Gutteridge, 1986; Saltveit and Morris, 1990). Under normal conditions, the antioxidant system is usually sufficient in preventing damage (Hideg, 1997). However, stressful environmental conditions impair the plant's natural capacity to dissipate excess light energy and scavenge oxygen radicals. When photosynthesis is inhibited by sustained exposure to low temperatures, the photosynthesis rate declines as a result of reduced metabolic rates. The plant becomes less efficient in converting light energy to carbohydrates. The excess energy produced by exposure to light leads to higher production of AOS (Asada, 1994; Massacci et al., 1995), which overloads the plant's defense system. This is one of the factors causing CI. The inherently higher photosynthetic activity in leaf 4 may have mitigated the degree of oxidative stress incited by low temperature, because there would be less resultant excessive energy to be quenched in the younger leaf than in older ones.

One of the mechanisms, then, for higher tolerance to chilling stress in a young leaf is the ability to produce more antioxidants, which resulted in higher antioxidant activity when exposed to low temperature (Fig. 6). This is parallel to earlier findings in which SOD transcripts and activities were induced, by photooxidative stress, in various cellular compartments of young barley leaves (Casano et al., 1994). Similarly, Pastori and Trippi (1993) found that the activities of several antioxidant enzymes, including SODs, were induced in young leaves by strong oxidants like paraquat and $\mathrm{H}_{2} \mathrm{O}_{2}$, but were reduced in senescent leaves of droughtsensitive maize strains. Small increases in the activities of GR and APX were observed in paraquat-tolerant pea leaves (Donahue et al., 1997). Antioxidant activity, at least for the APX enzyme, seemed to be developmentally regulated in that more isozymes were expressed in the young leaf compared with older leaves of untreated plants. These contributed to higher total APX activity in leaf 4 compared with older leaves when exposed to a chilling temperature (Fig. 5). Similarly, response to paraquat was different in the expanding and aged leaves, confirming the hypothesis that the reaction against photooxidative stress depends on the ontogenic state of the leaf (Casano et al., 1994; Kurepa et al., 1997).

Other studies have demonstrated the existence of crosstolerance to various oxidative stress-generating factors - biotic or abiotic. Cotton (Gossypium hirsutum L.) plants exposed to a water deficit were found to be more resistant to paraquat than water-replete plants, and ozone-tolerant tobacco (Nicotiana tabacum L.) cultivars showed cross-tolerance to paraquat (Burke et al., 1985; Shaaltiel et al., 1988). Inbred varieties of paraquat-tolerant maize also showed higher resistance to drought stress (Malan et al., 1990). In pea plants, resistance to sulfur dioxide was correlated with resistance to paraquat (Madamanchi et al., 1994). There is a universal systemic response to various stress factors (Hughes and Dunn, 1996). Therefore, different stresses produce similar effects at the cellular level (Bowler et al., 1992).

Apparently, the antioxidant defense mechanism is a systemic response in plants triggered by various kinds of stress. The differential response between old and young leaves indicate some developmental controls in the induction processes of plant defense. In the younger leaves of cucumber, increases in SOD, 
APX, and GR activities appeared to play an important role in chilling stress tolerance; however, they could not fully account for the high level of chilling stress tolerance observed. A mechanism other than increased enzyme activity must be in place to explain the high levels of chilling tolerance observed. One such mechanism may be a more active role of nonenzymatic antioxidants, such as ascorbic acid or glutathione (GSH), which have been observed to increase transiently after leaf exposure to low temperature (Wang, 1990). Further study will be needed to assess a detailed examination of both longterm, developmental, and faster acting stress-mediated mechanisms affecting the expression of the antioxidant gene in plants.

\section{Literature Cited}

Anderson, M.D., T.K. Prasad, and C.R. Stewart. 1995. Changes in isozyme profiles of catalase, peroxidase, and glutathione reductase during acclimation to chilling in mesocotyls of maize seedlings. Plant Physiol. 109:1247-1257.

Asada, K. 1994. Mechanisms for scavenging reactive molecules generated in chloroplasts under light stress, p. 129-140. In N.R. Baker (ed.). Photoinhibition of photosynthesis. Bios Scientific Publishers, Oxford, UK.

Basra, A.S. 2001. Crop responses and adaptations to temperature stress, p. 1-34. In T.K. Prasad (ed.). Mechanisms of chilling injury and tolerance. Haworth Press, New York.

Bowler, C.M., M. Van Montagu, and D. Inzé. 1992. Superoxide dismutase and stress tolerance. Annu. Rev. Plant Physiol. 43:83-116.

Bradford, M.M. 1976. A rapid and sensitive method for the quantification of microgram quantities of protein-dye binding. Anal. Biochem. 72:248-254.

Buege, J.A. and S.D. Aust. 1978. Microsomal lipid peroxidation. Methods Enzymol. 52:302-310.

Burke, J.J., P.E. Gamble, J.L. Hatfield, and J.E. Quisenberry. 1985. Plant morphological and biochemical responses to field water deficit. I. Responses of glutathione reductase activity and paraquat sensitivity. Plant Physiol. 79:415-419.

Butler, W.L. 1978. Energy distribution in the photochemical apparatus of photosynthesis. Annu. Rev. Plant Physiol. 29:345-378.

Casano, L.M., M. Martín, and B. Sabater. 1994. Sensitivity of superoxide dismutase transcript levels and activities to oxidative stress is lower mature-senescent than in young barley leaves. Plant Physiol. 106:1033-1039.

Chen, G.X. and K. Asada. 1989. Ascorbate peroxidase in tea leaves: Occurrence of two isozymes and the differences in their enzymatic and molecular properties. Plant Cell Physiol. 30:987-998.

Donahue, J.L., C.M. Okpodu, C.L. Cramer, E.A. Grabau, and R.G. Alscher. 1997. Responses of antioxidants to paraquat in pea leaves: Relationships to resistance. Plant Physiol. 113:249-257.

Du, Z. and W.J. Bramlage. 1992. Modified thiobarbituric acid assay measuring lipid oxidation in sugar-rich plant tissue extracts. J. Agr. Food Chem. 40:1566-1570.

Feierabend, J., C. Schaan, and B. Hertwig. 1992. Photoinactivation of catalase occurs under both high- and low-temperature stress conditions and accompanies photoinhibition of photosystem II. Plant Physiol. 100:1554-1561.

Guy, C.L. 1990. Cold acclimation and freezing stress tolerance: Role of protein metabolism. Annu. Rev. Plant Physiol. Plant Mol. Biol. 41:187-223.

Halliwell, B. and J.M.C. Gutteridge. 1986. Oxygen free radicals and iron in relation to biology and medicine: Some problems and concepts. Arch. Biochem. Biophys. 246:501-514.
Halliwell, B. and J.M.C. Gutteridge. 1989. Free radicals in biology and medicine. Clarendon Press, Oxford, UK.

Havaux, M. and A. Davaud. 1994. Photoinhibition of photosynthesis in chilled potato leaves is not correlated with a loss of photosystem II activity: Preferential inactivation of photosystem I. Photosynth. Res. 40:75-92.

Hetherington, S.E., J. He, and R.M. Smillie. 1989. Photoinhibition at low temperature in chilling-sensitive and -resistant plants. Plant Physiol. 90:1609-1615.

Hideg, E. 1997. Free radical production in photosynthesis under stress conditions, p. 911-930. In M. Pessarakli (ed.). Handbook of photosynthesis. Marcel Decker, New York.

Hodges, D.M., C.J. Andrews, D.A. Johnson, and R.I. Hamilton. 1997. Antioxidant enzyme responses to chilling stress on differentially sensitive inbred maize lines. J. Expt. Bot. 48:1105-1113.

Hughes, M.A. and M.A. Dunn. 1996. The molecular biology of plant acclimation to low temperature. J. Expt. Bot. 47:291-305.

Jackman, R.L., R.Y. Yada, A. Marangoni, K.L. Parkin, and D.W. Stanley. 1988. Chilling injury: A review of quality aspects. J. Food Sci. 11:253-277.

Jana, S. and M.A. Choudhuri. 1982. Glycolate metabolism of three submerged aquatic angiosperms during aging. Aquat. Bot. 12:345-354.

Krause, G.H., T.M. Briantais, and C. Vernott. 1983. Characterization of chlorophyll fluorescence spectroscopy at $77 \mathrm{~K}$. I. $\Delta \mathrm{pH}$-dependent quenching. Biochim. Biophys. Acta 723:169-175.

Kuk, Y.I., J.S. Shin, J.S. Chung, O.D. Kwon, D.K. Kim, O. Han, and J.O. Guh. 2003a. Differential tolerances and their mechanism on the response of tobacco (Nicotiana tabacum L.) leaves of varying ages to protoporphyrinogen oxidase-inhibiting herbicides and paraquat. Korean J. Weed Sci. 23:100-111.

Kuk, Y.I., J.S. Shin, H.I. Jung, J.O. Guh, S. Jung, and N.R. Burgos. 2006. Mechanism of tolerance to paraquat in cucumber leaves of various ages. Weed Sci. 54:6-15.

Kuk, Y.I., J.H. Lee, H.Y. Kim, S.J. Chung, G.C. Chung, J.O. Guh, H.J. Lee, and N.R. Burgos. 2003b. Relationships of cold acclimation and antioxidative enzymes with chilling tolerance in cucumber (Cucumis sativus L.). J. Amer. Soc. Hort. Sci. 128:661-666.

Kurepa, J., D. Hérouart, M. Van Montagu, and D. Inzé. 1997. Differential expression of $\mathrm{CuZn}$ - and Fe-superoxide dismutase genes of tobacco during development, oxidative stress, and hormonal treatments. Plant Cell Physiol. 38:721-730.

Laemmli, U.K. 1970. Cleavage of structural proteins during the assembly of the head of bacteriophage $\mathrm{T}_{4}$. Nature 227:680-685.

Madamanchi, N.R., X. Yu, A. Doulis, R.G. Alscher, K.K. Hatzios, and C.L. Cramer. 1994. Acquired resistance to herbicides in pea cultivars through pretreatment with sulphur dioxide. Pesticide Biochem. Physiol. 48:31-40.

Malan, C., M.M. Greyling, and J. Gressel. 1990. Correlation between $\mathrm{CuZn}$ superoxide dismutase and glutathione reductase, and environmental and xenobiotic stress tolerance in maize inbreds. Plant Sci. 69:157-166.

Massacci, A., M.A. Iannelli, F. Pietrini, and F. Loreto. 1995. The effect of growth at low temperature on photosynthetic characteristics and mechanisms of photoprotection of maize leaves. J. Expt. Bot. 46:119-127.

Mishra, N.P., R.K. Mishra, and G.S. Singhal. 1993. Changes in the activities of antioxidant enzymes during exposure of intact wheat leaves of strong visible light at different temperature in the presence of protein synthesis inhibitors. Plant Physiol. 102:903-910.

Mittler, R. and B. Zilinskas. 1993. Detection of ascorbate peroxidase activity in native gels by inhibition of the ascorbate-dependent reduction of nitroblue tetrazolium. Anal. Biochem. 212:540-546.

Oidaira, H., S. Satoshi, K. Tomokazu, and U. Takashi. 2000. Enhancement of antioxidant enzyme activities in chilled rice seedlings. Plant Physiol. 156:811-813.

Omran, R.J. 1980. Peroxide levels and the activities of catalase, peroxidase, and indole acetic acid oxidase during and after chilling cucumber seedling. Plant Physiol. 65:407-408. 
Pastori, G.M. and V.S. Trippi. 1993. Antioxidative protection in a drought-resistant maize strain during leaf senescence. Physiol. Plant. 87:227-231.

Prasad, T.K. 1996. Mechanisms of chilling-induced oxidative stress injury and tolerance: Changes in antioxidant system, oxidation of proteins and lipids, and protease activities. Plant J. 10: $1017-1026$.

Rao, M.V., G. Paliyath, and D.P. Ormrod. 1996. Ultraviolet-B- and ozone-induced biochemical changes in antioxidant enzymes of Arabidopsis thaliana. Plant Physiol. 110:125-136.

Reyes, E. and P.H. Jennings. 1994. Response of cucumber (Cucumis sativus L.) and squash (Cucurbita pepo L. var: Melopepo) roots to chilling stress during early stages of seeding development. J. Amer. Soc. Hort. Sci. 119:964-970.

Saltveit, M.E. and L.L. Morris. 1990. Overview of chilling injury of horticultural crops, p. 3-15. In C.Y. Wang (ed.). Chilling injury of horticultural crops. CRC Press, Boca Raton, Fla.

Saruyama, H. and M. Tanida. 1995. Effect of chilling on activated oxygen-scavenging enzymes in low temperature-sensitive and -tolerant cultivars of rice (Oryza sativa L.). Plant Sci. 109: 105-113.

Shaaltiel, Y., A. Glazer, P.F. Bocion, and J. Gressel. 1988. Crosstolerance to herbicidal and environmental oxidants of plant biotypes tolerant to paraquat, sulphur dioxide, and ozone. Pesticide Biochem. Physiol. 31:13-19.

Shen, W., K. Nada, and S. Tachibana. 1999. Effect of chilling treatment on enzymic and nonenzymic antioxidant activities in leaves of chilling tolerant and chilling sensitive cucumber (Cucumis sativus L.) cultivars. J. Jpn. Soc. Hort. Sci. 68:967-973.

Sherman, T.D., J.M. Becerril, H. Matsumoto, M.V. Duke, J.M. Jacobs, N.J. Jacobs, and S.O. Duke. 1991. Physiological basis for differential sensitivities of plant species to protoporphyrinogen oxidaseinhibiting herbicides. Plant Physiol. 97:280-287.

Spychalla, J.P. and S.L. Desborough. 1990. Superoxide dismutase, catalase, and $\alpha$-tocopherol content of stored potato tubers. Plant Physiol. 94:1214-1218.

Terashima, I., S. Funayama, and K. Sonike. 1994. The site of photoinhibition in leaves of Cucumis sativus L. at low temperatures is photosystem I, not photosystem II. Planta 193:300-306.

Wang, C.Y. 1990. Alleviation of chilling injury of horticultural crops, p. 281-302. In C.Y. Wang (ed.). Chilling injury of horticultural crops, CRC Press, Boca Raton, Fla.

Wise, R.R. and A.W. Naylor. 1987. The peroxidative destruction of lipids during chilling injury to photosynthesis and ultrastructure. Plant Physiol. 83:272-277. 